\title{
A Threshold Concept in Managing: What Students in Introductory Management Courses Must Know
}

Journal of Management Education 20I7, Vol. 4I(6) 835-85I

(C) The Author(s) 2017

Reprints and permissions: sagepub.com/journalsPermissions.nav DOI: $10.1177 / 1052562917704869$ journals.sagepub.com/home/jme

(S)AGE

\section{Paul Donovan'}

\begin{abstract}
In the field of management, a practice-theory gap has developed and consequently, management education has been criticized for being irrelevant to the needs of stakeholders. This article argues that introduction to management courses in higher education perpetuate this gap by not teaching what managers do. These courses fail to communicate well the threshold concept of managing as accomplishing results through other people. Understanding this threshold concept would give students clearer perspectives on the distinction between doing work and managing work in organizations - between being "one of the team" and "managing the team." Using a class exercise as exemplar, the author demonstrates the use of a set of debate questions in the form of contestable statements regarding doing and managing, which are argued by students in small groups in class before final resolution in a plenary session. Students emerge from these debating sessions with a clearer definition and understanding of the core work that managers actually do. Learners also become cognizant of the need for managers to have an appropriate balance between the amount of managing
\end{abstract}

This article is part of the Special Issue "Introduction to Management Courses"

IMaynooth University, Maynooth, Kildare, Ireland

\section{Corresponding Author:}

Paul Donovan, School of Business, Maynooth University, Rye Hall Extension, Maynooth

Campus, Kildare I, Ireland.

Email: paul.donovan@nuim.ie 
and doing work they engage in on a daily basis. Without these understandings students become "stuck" and their learning lacks posteducational relevance.

\section{Keywords}

management education, threshold concept, doing, managing work, introduction to management

A research-practice gap has emerged in the field of management and accordingly, management education (ME) has regularly been criticized as lacking relevance (Mintzberg, 1973, 2004; Mintzberg \& Gosling, 2002; Stewart, 1984). In recent times, the pace of organizational change has seemed to outstrip the ability of higher education to keep up and accordingly, the adaptability of ME to the relentlessly transforming processes of globalization has been challenged (Sheppard, 2015). Recent research has also indicated that introduction to management textbooks are learning inhibitory suggesting that ME courses constitute a poor introduction to management for undergraduate students (Snyder, 2014). Critical management education literature derides ME for its "sustainability paradox," that is, supporting dominant approaches to wealth generation that corrode ecological systems and the network relationships on which their survival depends (Kurucz, Colbert, \& Marcus, 2014). Additionally, management study and practice are portrayed as being reproductive of the status quo, supportive of organizational survival and controlling of workers (Fenwick, 2005). Also from a philosophical standpoint, $\mathrm{ME}$ is accused of the adoption of utilitarianism and the interests of the power elites (Fenwick, 2005; Painter-Morland, 2015).

In this article, I expose how the threshold concept of what managing work actually is offers a way of clarifying the job of the manager in the introductory management course especially at the undergraduate level. The concept of managing work emerges from a classical definition of managementachieving results through others (Loen, 1971). Although this is regarded as a foundational concept, it is remarkable that introductory management textbooks devote little if any space to the idea. A lack of understanding of a threshold concept renders the student likely to get "stuck" in a cycle of ritual memorizing of ideas without fully grasping the core disciplinary ideas and practice and leaves them also without a foundation for their further study in the field (Meyer, 2003).

The remainder of this article is as follows: I review the literature on criticisms of ME and on threshold concepts. These reviews show that the introductory management textbooks and, consequently, introductory management 
courses are bereft of a threshold concept critical for student learning. From these reviews, I propose that there is a deficiency in ME with respect to the threshold concept of what managing work is. I illustrate a specific courselearning activity using a set of debate questions posed on the subject of management work versus doing work. Learners are encouraged to distinguish between both sets of activities through debate. Gaining perspectives on these critical differences provides learners with a valuable contribution toward their understanding of the work of the manager, thus enabling them in their future roles as managers to negotiate more effectively the transition from being an individual contributor to becoming the manager of the context and activities of others.

\section{Criticizing Management Education}

Management and ME lack recognition as major contributors to global welfare. Bloom, Genakos, Sadun, and Van Reenen (2012) report that management has been largely ignored by economists as a driving factor explaining differences in productivity. This may originate in part from the limited scope that ME adopts in terms of its scholarly contribution to society, such scope emanating from an emphasis in ME on the improvement of current management practices rather than the development of leadership for future human benefit (Waldman, De Luque, \& Wang, 2012). The academy is further criticized for failing to engage enough with practitioners and with the problems being faced by organizations - an engagement that could lead to many sources of knowledge being brought to bear on important organizational and societal issues (Mohrman \& Lawler, 2012).

Business schools today face the challenge of relevance aimed at them by the stakeholders they purport to serve (Cannon, 2015). This challenge is not a novel one and academics have had the "irrelevant" term thrown at them for decades. The Ford and Carnegie Foundation Reports in the middle of the past century were a harbinger of things to come in the way they criticized business schools for being too academic (Gordon \& Howell, 1959). Accordingly, a research-practice gap has emerged and has begun to attract the attention of scholars even though practitioners seem to have had an untroubled awareness of it for some time. Although there is a certain consensus about its existence, the cause of the research-practice gap in management is a more contested concept. Some authors propose "management . . . as a practice informed by theory" (Wright \& Gilmore, 2012, p. 616) but this is strongly contested by others who declare that academics and practitioners plough different furrows. Recently, Bartunek and Rynes (2014) point to differences between academics and practitioners including styles, rigor, relevance, and interests and 
incentives. Consequently, they contend that practitioner voices are absent in academic research and academic teaching. However, such declarations fail to attribute a cause to the divide. Mintzberg (1973) is more direct however, focusing more on the business school curriculum, "the management school . . . does not in fact teach them how to manage, and the world is full of highly competent managers who have never spent one day in a management course" (p. 187). Mintzberg has sustained this trenchant criticism over time and has berated business schools for promoting largely irrelevant curricula (Mintzberg, 1989, 2004; Mintzberg \& Lampel, 2001). Pfeffer and Fong (2002) agree, "Neither possessing an MBA degree nor grades earned in courses correlate with career success, results that question the effectiveness of schools in preparing their students" (p. 78).

The research-practice gap in management is also reflected in the criticisms directed at management textbooks that are used in universities in introduction to management courses. The textbook is still a staple requirement of business schools largely due to the benefits it brings to teaching and in the vast majority of universities ME courses are textbook based (Errington \& Bubna-Litic, 2015). Program directors declare certain texts as mandatory and this provides a control mechanism ensuring that several editions of the same class and year experience the same content. Publishers also have been active in producing support materials as an aid to lecturers to make the task of developing materials for teaching that much easier. These materials included MS PowerPoint slides, case studies, examination questions, multiple choices tests, and audio visual supplementary items. A text which offers teaching supports is likely to gain favor among hard-pressed teachers with burgeoning class sizes.

Management text books however, have come under increasing attack from academics and students. Students are dismayed at high prices for single texts when they perceive that the same information, available on the Internet, is free. Snyder (2014) describes introduction to management text books as learning inhibitory with the admonition Let's Burn Them All. He outlines several limitations to these texts including the absence of recent neuroscience findings, ineffective presentation of theories, the use of confusing academic language, and the nonengaging way the material is presented. More tellingly, Snyder (2014) exposes a striking similarity in content between the most popular introductory management textbooks today-content that also places little emphasis on defining managing work.

The practice-theory gap in ME however, extends further than the textbook. There are problems also with curricula. The curricula of management courses is where students learn about organizations but not about managing them or their people (David \& David, 2011). Although Wright and Gilmore (2012) argue for a practice informed by theory much of what passes for ME 
does not bear much resemblance to the life of organizations. Bennis and O'Toole (2005) criticize ME for "failing to impart useful skills, failing to prepare leaders and even failing to lead graduates to good corporate jobs" (p. 96). There is increasing evidence to suggest that a graduate's ME has illprepared them for succeeding in business (Pfeffer \& Fong, 2002). A study on required license certifications that companies desire persons to have to take up posts in management revealed a significant difference between organizational requirements and what was being taught at university (David \& David, 2011). If students enroll in ME in the hope of being trained for work in management, they will encounter an education program that focuses on the functions of business more than the practice of managing (Mintzberg \& Gosling, 2002). It is this theme of managing that I continue with in the next section discussing the nature of managing work and its role as a threshold concept that ME fails to deal with adequately.

\section{Managing Work as a Threshold Concept}

What do managers do? In asking this question in the early years of the $70 \mathrm{~s}$ decade, Henry Mintzberg (1973) challenged ME to deliver a response to the complex needs of managers in modern organizations. In the earlier part of that century, from Fayol to Follett, the work of the manager was described in terms of a clean-limbed set of roles-plan, lead, organize, control. Business schools quickly adopted the concept and taught the job of the manager using bounded case studies that could be resolved using rational decision making and linear problem solving approaches. Mintzberg's principal contribution was to challenge this orthodoxy by portraying the job of the manager as fragmentary, reactive, and seemingly chaotic. In doing this, Mintzberg offered an alternative point of view that strongly contested the earlier taxonomic approach. Another major contribution from Mintzberg's (1973) research was to portray the manager's job as a set of roles: figurehead, leader, liaison, monitor, disseminator, spokesperson, entrepreneur, disturbance handler, resource allocator, and negotiator. Although these roles are helpful, and a departure from the rational approach, Mintzberg (2015) still laments their inadequacy in helping managers to execute their job effectively. In other words, he asserts that we still do not know enough about what managers actually do.

The inattention in the management literature to the specific job of the manager provides real challenges for ME institutions and for students. Institutions, established to teach management in so-called management programs, are, in actuality, teaching organization studies. Degree programs are organized around topics such as organization theory, organization behavior, accounting, economics, and so forth, but rarely do we see the job of the 
manager as a module title. For the students, they emerge from their degree in management without having the skills to practice it (Mintzberg, 1973). This is an idea unthinkable in medicine or engineering, or many other disciplines. Additionally, it is unclear if the skills and behaviors attributed to managers and management in these programs are in any way exclusively managerial in nature (Hales, 1986). For management and ME, this is a serious criticism which challenges the ability of business schools to claim to be the preparatory nurseries and licensing authorities of business managers as these schools do not clearly define and teach managing as distinct from nonmanaging activities.

In short, the studies have not demonstrated that there is a bounded and separate set of activities which may be called "managerial work" - and not merely activities which managers have been shown to do. (Hales, 1986, p. 109).

There is no shortage of management and organization behavior textbooks with a definition of managing. Most of them follow a similar path describing the job of the manager as achieving results through other people or some variation of this general approach. However, they fail to further elaborate exactly what distinguishes those on whom is conferred the title of manager from individual contributors, or nonmanagers.

One worthy exception to the above rule is the work of Loen who, in the 1970 s, contrasted what managers do with what managers get others to do (Loen, 1971). In this work, Loen elaborated the difference between achieving results through other people - managing and achieving results by one's own actions alone-doing. Where this work is helpful is in distinguishing the difference between managing and nonmanaging (doing) work. It responds comprehensively to the challenge of Hales (1986, p. 109) by identifying the differentia specifica of the manager's and nonmanager's jobs.

This distinction is of critical importance as much to the student of management as it is to the practicing manager. It is the rare organization that can afford to have staff on the payroll who do nothing else but manage others. It would also be inefficient if organizations were to promote, from the shopfloor to managerial positions, persons who continued to perform only the duties they held as individual contributors - doing an operator's work for a manager's salary. Managers need to understand the distinction between managing and doing and they need to divine an ongoing balance between these two approaches that is appropriate to their context. Successful managers, irrespective of their education or alma mater, understand this balance. The complaints of those who rail against ME ring around this specific issue-the knowledge of what managing work is. This knowledge is in itself a threshold 
concept of managing - one that is underdescribed in the management literature and one that is also difficult to find in introductory management courses, resulting in the consistent criticisms of ME.

Meyer and Land (2003) in introducing threshold concepts described them as ways of accessing subject matter that was previously inaccessible to the novice or learner. Apprehension of the threshold concept is described as being "transformative (occasioning a significant shift in the perception of a subject), irreversible (unlikely to be forgotten, or unlearned only through considerable effort), and integrative (exposing the previously hidden interrelatedness of something)" (Meyer \& Land, 2005, p. 373). Examples of threshold concepts are depreciation in accounting, entropy in physics, and pain in physiology (Meyer \& Land, 2005). Does managing work qualify as a threshold concept? According to Meyer and Land (2003), a threshold concept requires five characteristics, those being, transformative, irreversible, integrative, bounded, and troublesome. The threshold concept of managing work is transformative. With this concept the student learns that managing work is distinguished from doing work because managing is getting others to do the work (Stewart, 1984). This is transformative because their worldview of manager as power boss is dispelled and a view of manager as influencer emerges. The threshold concept is irreversible. When students apprehend this concept, they understand how effective managers do not necessarily "know more" than workers do neither can they necessarily perform the frontline tasks as well as their employees can do. This becomes an irreversible understanding of the essence of managing work. This threshold concept is also integrative in that students, when they acquire the concept of managing work, can see the relationships between other concepts such as leadership, delegation, and motivation. The managing work threshold concept is bounded. When students perceive managing as achieving results through others, they also recognize how it is a qualitatively different discipline to others such as engineering or medicine in that these practitioners achieve results through their own efforts. The managing work threshold concept is also troublesome. The appreciation of managing as the management of context as opposed to managing as the commanding of others can be counterintuitive to students who have learned contradictory concepts from popular culture and social media and so they may temporarily resist this level of understanding.

Educators may now identify how threshold concepts can inform their curriculum development and course design (Wright \& Gilmore, 2012). The journey of the student toward a deep learning and a comprehensive understanding of the field is supported by the discovery of introductory portals that beckon toward the transformational landscape. Without this beckoning, students may remain outside of the portals of understanding and may fail to see things in a 
new way and become "stuck" in surface learning rather than pass into deeper understanding (Davies \& Mangan, 2007). Such learners may become unable to understand future concepts in their studies that are based on prior learning and may continue to resort to superficial rote learning which is soon lost after the assessment has passed (Wright \& Gilmore, 2012). I go on now to explain an example of how the concept of what management work actually is was employed in a class exercise to scaffold undergraduate learners in the quest to distinguish managing work from nonmanaging work.

\section{Exercise Overview}

This exercise is suitable for undergraduate and graduate students in introduction to management and organizational behavior courses. The exercise involves the use of an instrument in the form of a set of contestable statements around the topic of managing work which are analyzed and discussed by students. Each statement is deliberately written to provoke discussion and debate and is easily contestable by students who have only a limited experience of the workplace. The exercise can be successfully executed in a 50-minute class session and requires a brief introduction and no homework in advance of the class. While each lecturer will have their own preferred approach for delivering the exercise, my favorite way is to introduce the concept of managing work in an interactive and engaging manner. I then form groups of students to debate the statements as follows: Is this managing or doing work? After about 20 minutes, I reassemble the students in plenary, discuss the outcomes of their debates, attempt to resolve remaining conflicts, and scaffold the learning further. The overall exercise has two principal learning objectives:

1. Students will be able to define managing work.

2. Students will be able to distinguish managing work from doing work.

\section{Conducting the Exercise}

The exercise commences with a discussion on what managing is. I usually do this in a Socratic manner beginning with the question in open session, what is managing? I follow this question up by saying that I want to reach a definition of managing and push on by asking students what they think managers get paid for in organizations. Students typically begin to contribute answers such as deciding, or solving problems or delegating and if I have space and time I usually note these on a whiteboard. As we go, I gently reject these as a definition of managing replying that organizations really do not pay 
managers just for decision making or problem solving. Finally after a few minutes, we get there and someone will offer results. Writing on the whiteboard I commence my definition of managing as managing is getting results. Then, I challenge the students to explain how that is different from the gardener or painter outside who are also paid for results. We quickly arrive at a definition that managing is getting results through other people.

At the start of the exercise, I issue everyone with the handout (see Table 1) containing the managing-doing instrument made up of 20 statements, each of which can either imply managing or doing (Loen, 1971). I set up debating groups throughout the class, making teams of five people each. Within each team I choose one person to act as facilitator of the debate. The other four persons are divided into pairs - one pair should argue that the statement implies managing and the other pair will argue that the statement implies doing (nonmanaging). I allocate specific statements to each group, normally about 2 statements per group, so that groups will return to plenary with something slightly different to their colleagues in other groups. I recommend to facilitators that they get the pairs to switch roles after the first statement, that is, the "managing" group changes to "doing" and vice versa. Before the group returns to plenary they are required to complete the instrument fully as a team and without acting in the role of "managing" or "doing." This exercise usually takes 25 minutes to complete.

When students have completed the instrument I conduct a discussion in plenary, first asking some of the facilitators and groups to summarize their discussions and what they have learned from the exercise. At this point, I can deal with some of the issues and controversies that have emerged. I then issue the suggested answers to the instrument (see Table 2) for discussion.

As I take the group through the suggested answers, it is not unusual for a debate on some of the issues to recommence and the discussion can often be lively and engaged. The length of time to conduct this part of the session varies but should not be longer than 15 minutes as there is usually considerable agreement on most issues by this time. When I feel that the learning objectives have been achieved, I conclude the session and collect feedback, the content of which attests to the efficacy of the method and which is discussed in the next section.

\section{Evidence of Use and Effectiveness}

I have utilized this approach between 1991 and 2009 during the time I worked as management specialist in a prominent ME center with responsibility for teaching introduction to management courses for newly appointed supervisors and managers from public, private, and not-for-profit sectors. From 2011 
Table I. Managing-Doing Instrument.

Is this managing or doing?

Managing/Doing

I. Making a call with one of your people to assist him in
solving a technical problem.

Note: British spellings have been retained.

Source: Loen (197I).

to date, I continued to use the approach while teaching introduction to management modules during my work as senior lecturer in a school of business at a national university. The numbers of classes and students involved are listed in Table 3. 
Table 2. Suggested Answers to Managing-Doing Instrument.

Suggested answers to instrument: Is this managing or doing?

Doing-The stated purpose of the call is to assist in solving a technical problem rather than to perform managing elements such as training or supervising.

Doing-For two reasons. Signing cheques is a clerical or mechanical function: approving routine expenditures should generally be delegated with a defined procedure and with provision for an occasional compliance audit.

Doing-This is a personnel function. Deciding whether to hire someone after the recruiting, screening, and selecting have been done would be staffing, an element of managing.

Doing-This is not managing, unless you at least ask your subordinates for a recommended solution.

Managing-This is supervising or training since a new employee is involved. A new employee would have little or no basis for suggesting a solution to any work problem-whether recurring or new.

Managing-This is training.

Doing-The purpose or your phone call is not to get results through your subordinate but rather for him or her.

Doing-Filling out the form is clerical. Instructing your secretary to complete the form would be managing in that it would be delegating.

Managing-This is motivating.

Managing-This is developing your organisation structure.

Managing-This is communicating, for purpose of planning a policy, procedure, programme, or the like. It could also be a form of motivating if your proposal is to get participation now as a prelude to your getting acceptance later.

Managing-This is correcting - taking corrective control action. It could also be the disciplining part of supervising.

Managing-This is the measuring part of controlling.

Doing-This is a public relations function you are doing because you are not trying to get results through your people.

Doing-You may have to do it if there is no one else to do it, but this is a specialised methods engineering or systems and procedures function that can be performed by an individual doer.

Managing-You are developing your programme when you consider which resources your people should utilise to achieve or exceed objectives.

Managing-You are planning: developing your budget. Putting the budget in its proper form would be clerical, a doing activity.

Doing - The stated purpose of your attendance is to learn detailed technical developments. Generally, only specialists (individual doers) need to know technical developments in detail.

Doing-This is a public relations function.

Managing - This is communicating for the purposes of control-assuming you do so to receive possible guidance and direction. Otherwise, it is plain communicating which anyone does whether or not he/she is a manager.

Note: British spellings have been retained.

Source: Loen (197I).

Between 1990 and 2009 with the postexperience learners I used standard evaluation practices for my classes. The most widely known and applied approach to the evaluation of training and development programs is 
Table 3. Details of Classes Where Approach Was Used.

\begin{tabular}{lcccc}
\hline & Classes & Learner types & Learners & Evaluation used \\
\hline 1991 to 2009 & 98 & Postexperience & 1,176 & Reaction \\
201I to date & 14 & UG and PG & 980 & Reaction/written assessment \\
\hline
\end{tabular}

Kirkpatrick's four-level model (Smidt, Balandin, Sigafoos, \& Reed, 2009). This model recommends evaluation at reaction, learning, behavior, and results levels. Reaction Level assesses how individuals perceived and appreciated the training. Learning Level is the evaluation of the change in knowledge, skills, or attitudes that occurred as a result of the program. Behavior Level measures the change in postprogram behavior. The Results Level assesses the impact on the organization that occurred as a result of the program (Kirkpatrick, 1994). For the above programs, I used Kirkpatrick's Levels 1, 2, and 3. Accordingly, and for all programs, participants were surveyed for their reactions at program's end using an end-of-program questionnaire - typically known as the "happy sheet." In addition, the learning objectives were evaluated in the case of each individual using the managing-doing instrument and finally, sample tests were made to ascertain if postprogram behavior had changed as intended back on the job. Postprogram reviews of participants' comments the reaction evaluations (Level 1) indicated an appreciation by participants of the managing-doing concept. The Learning evaluation (Level 2) conducted during the programs using the managing-doing instrument showed the consistent ability in participants to distinguish managing work from doing work as indicated by the results of the exercise described in this article. Finally, the Behavior evaluation (Level 3) showed positive postprogram changes in behavior in distinguishing managing and doing work. These individual responses to the effectiveness of the managing-doing approach gave testament to the perception of effectiveness held by these learners. A social desirability effect is possible as an alternative explanation for the above declarations of effectiveness. However, this management center was and is a commercial concern and could survive only by delivering a suite of programs that participants found effective and comprised learning that participants could apply for improved organizational impact back on the job. Many participants on the programs were small business owners who had an incentive to seek value for money at all times and were never shy about criticizing material they felt did not work or was irrelevant to them. Yet these individuals also concurred with their colleagues about the effectiveness of the managing-doing approach.

I have also used the managing-doing exercise on the undergraduate and postgraduate business and management programs at my university over the 
period from 2011 to date. In these programs, the exercise was conducted as described in this article. Two specific examples of the use of this tool in this university setting are described as follows: I gathered feedback from undergraduate students studying a Strategic Human Resource Module as a part of their Bachelor in Business Management Program. After completing the managing versus doing exercise, the students $(n=44)$ were asked to complete a Student Questionnaire (see Appendix A). Where questions were asked on a 5-point Likert-type scale ranging in response from strongly agree to strongly disagree. The average age was 20.8 years with 2.8 years of university attendance. The students reacted well to the exercise with over $93 \%$ of them $(n=$ 44) agreeing they enjoyed the exercise; $93 \%(n=44)$ agreeing that it increased their understanding of managerial work. The most common comment in response to the "takeaway" question was that it helped them understand that managing was "getting work done through other people." Students were also asked, "What relationship, if any, do you see between the work managers do and the tasks of leadership, delegation, and the motivation of people?" For this question, students were given a comment box and from a response rate of $(n=37)$ the representative comments included "a strong relationship," "they are tied together in the tasks of a work manager," "the work of a good manager would be the tasks of leadership, delegation and motivation," "the relationship between these is key," "managing work links with leadership, delegation and motivation," and "that they must be linked in order to get results." In response to the question "I would recommend using this type of exercise in future," over $93 \%(n=44)$ agreed.

I have also used the exercise with postexperience master's students in the same business school. A student questionnaire was issued online following the exercise (see Appendix B). Where questions were asked on a 5-point Likert-type scale ranging in response from strongly agree to strongly disagree. Twelve students responded $(n=12)$ giving a response rate of $75 \%$. The average age was 33.8 with 3.25 years of university attendance. The students reacted very favorably to the exercise with $100 \%(n=12)$ agreeing that they found the session useful. Students were also asked "What was the most valuable thing you learned at the event?" and some representative comments included, "The most important think I got from this was the importance of delegating work to help develop employees," "I learned that managing is also training others," "Managers must oversee the tasks that employees do," and "Be prepared to delegate to your team both to allow them to develop and also to show them that you trust them." Students were also asked "How will your new knowledge of managing-doing help you manage better in the workplace?" and representative responses were "the insight on how to develop employees was also very useful," "understanding what work I can delegate to 
employees to develop them," "shown me where I can develop my team further," "shown me to take control of a situation or else delegate it to another."

The results shown here are consistent each time the exercise is deployed. I found that the feature of introducing the managing-doing concept in a Socratic manner enabled the students to tackle the debate with considerable skill despite the lack of experience in the world of work especially with undergraduates. The comments given by these two groups show that the exercise has been well received by students, has allowed them to learn the difference between managing and doing, and has shown that as a threshold concept, managing-doing enables the learner to grasp the "rules of the game" for managers in that, in order to get work done through other people, they must also develop, lead, and motivate their staff. Following the debate and plenary discussion, they emerged with a working understanding of the distinction between managing and doing work which is not only the objective of the exercise but allows to access understanding that the role of the manager in getting work done through other people is to give leadership, motivation, and to develop employees. Further research is warranted, perhaps in terms of longitudinal studies, to examine if the knowledge gained in these sessions continues to be applied in the postlearning situation. This may include qualitative research with alumni to see if they refer unprompted to the managingdoing concept as one which they continue to use and find useful in their management roles.

\section{Conclusion}

Management literature often bears little resemblance to management practice (Bansal, Bertels, Ewart, MacConnachie, \& O'Brien, 2012). Bennis and O'Toole (2005) cite business schools' obsession with scientific research as cause - an obsession that prevents academia giving the help that managers actually need. Others censure these schools for providing management curricula that are divorced from the needs of organizations and managers (David \& David, 2011). Business schools do not teach what managers actually do (Mintzberg, 2015). This article suggests that students of introduction to management courses are not well served because such programs do not teach the threshold concept of what managing work actually is. As a result, these students become stuck, being unable to understand how a range of management concepts are linked. This article provides an exercise as exemplar for teaching of the threshold concept of managing work in introduction to management courses. This exercise enables students to understand the concept of managing work through learning how to distinguish between work that is "managing" and work that is "doing," that is, nonmanaging. Furthermore, it 
enables them to see how a manager's responsibility is to lead, motivate, and develop their staff.

\section{Appendix A}

1. I enjoyed the exercise.

2. The exercise increased my understanding of managing work.

3. What are your most important "takeaways" from this session?

4. How did this exercise help you understand the difference between managing and doing?

5. What relationship, if any, do you see between the work managers do and the tasks of leadership, delegation, and the motivation of people?

6. I would recommend using this type of exercise in future.

\section{Appendix B}

1. I found the session on managing/doing useful.

2. What was the single most valuable thing you learned at the event?

3. How will your new knowledge of managing/doing help you manage better in the workplace?

\section{Declaration of Conflicting Interests}

The author(s) declared no potential conflicts of interest with respect to the research, authorship, and/or publication of this article.

\section{Funding}

The author(s) received no financial support for the research, authorship, and/or publication of this article.

\section{References}

Bansal, P., Bertels, S., Ewart, T., MacConnachie, P., \& O'Brien, J. (2012). Bridging the research-practice gap. Academy of Management Perspectives, 26(1), 73-92. doi:10.5465/amp.2011.0140

Bartunek, J. M., \& Rynes, S. L. (2014). Academics and practitioners are alike and unlike: The paradoxes of academic-practitioner relationships. Journal of Management, 40, 1181-1201.

Bennis, W. G., \& O'Toole, J. (2005). How business schools lost their way. Harvard Business Review, 83(5), 96-104.

Bloom, N., Genakos, C., Sadun, R., \& Van Reenen, J. (2012). Management practices across firms and countries. Academy of Management Perspectives, 26(1), 12-33. doi:10.5465/amp.2011.0077 
Cannon, T.(2015). Business schools becomeirrelevant. Financial Times. Retrieved from http://www.ft.com/cms/s/2/c42306b2-263e-11e5-bd83-71cb60e8f08c.html\#axz z4FWViNu1B

David, F. R., \& David, F. R. (2011). Comparing management curricula with management practice. SAM Advanced Management Journal, 76(3), 48-55.

Davies, P., \& Mangan, J. (2007). Threshold concepts and the integration of understanding in economics. Studies in Higher Education, 32, 711-726. doi: $10.1080 / 03075070701685148$

Errington, A., \& Bubna-Litic, D. (2015). Management by textbook: The role of textbooks in developing critical thinking. Journal of Management Education, 39, 774-800. doi:10.1177/1052562915594839

Fenwick, T. (2005). Ethical dilemmas of critical management education: Within classrooms and beyond. Management Learning, 36, 31-48. doi:10.1177/1350507605049899

Gordon, R., \& Howell, J. (1959). Higher education for business. New York, NY: Columbia University Press.

Hales, C. P. (1986). What do managers do? A critical review of the evidence. Journal of Management Studies, 23, 88-115.

Kirkpatrick, D. L. (1994). Evaluating training programs. San Francisco, CA: BerrettKoehler.

Kurucz, E. C., Colbert, B. A., \& Marcus, J. (2014). Sustainability as a provocation to rethink management education: Building a progressive educative practice. Management Learning, 45, 437-457.

Loen, R. O. (1971). Manage more by doing less. New York, NY: McGraw-Hill.

Meyer, J. H. F., \& Land, R. (2003). Threshold concepts and troublesome knowledge: Linkages to thinking and practising within the disciplines. In C. Rust (Ed.), Improving student learning: Theory and practice-ten years on (pp. 412-424). Oxford, England: Centre for Staff Learning and Development.

Meyer, J. H. F., \& Land, R. (2005). Threshold concepts and troublesome knowledge (2): Epistemological considerations and a conceptual framework for teaching and learning. Higher Education, 49, 373-388.

Meyer, J. P. (2003). Four territories of experience: A developmental action inquiry approach to outdoor-adventure experiential learning. Academy of Management Learning \& Education, 2, 352-363.

Mintzberg, H. (1973). The nature of managerial work. New York, NY: Harper \& Row.

Mintzberg, H. (1989). Mintzberg on management. New York, NY: Macmillan.

Mintzberg, H. (2004). Managers, not MBAs: A hard look at the soft practice of managing and management development. San Francisco, CA: Berrett-Koehler.

Mintzberg, H. (2015). The Nature of Managerial Work (1973) \& Simply Managing: What Manager Do - and Can Do Better(2013).M@n@gement, 18, 186-188.

Mintzberg, H., \& Gosling, J. H. (2002). Reality programming for MBAs. Strategy and Business, 26(1), 28-31.

Mintzberg, H., \& Lampel, J. (2001). Do MBAs make better CEOs? Sorry, Dubya, It ain't necessarily so. Fortune International (Europe), 143(4), 105. 
Mohrman, S. A., \& Lawler, E. E. III. (2012). Generating knowledge that drives change. Academy of Management Perspectives, 26(1), 41-51. doi:10.5465/ amp.2011.0141

Painter-Morland, M. (2015). Philosophical assumptions undermining responsible management education. Journal of Management Development, 34, 61-75. doi:10.1108/JMD-06-2014-0060

Pfeffer, J., \& Fong, C. T. (2002). The end of business schools? Less success than meets the eye. Academy of Management Learning \& Education, 1, 78-95. doi:10.5465/ AMLE.2002.7373679

Sheppard, E. (2015). Practice Weeks @ Bedfordshire: An innovative response to criticisms of management education. International Journal of Management Education, 13, 106-117.

Smidt, A., Balandin, S., Sigafoos, J., \& Reed, V. A. (2009). The Kirkpatrick model: A useful tool for evaluating training outcomes. Journal of Intellectual \& Developmental Disability, 34, 266-274. doi:10.1080/13668250903093125

Snyder, R. A. (2014). Let's burn them all: Reflections on the learning-inhibitory nature of Introduction to Management and Introduction to Organizational Behavior textbooks. Journal of Management Education, 38, 733-758. doi:10.1177/1052562913502481

Stewart, R. (1984). The nature of management? A problem for management education. Journal of Management Studies, 21, 323-330.

Waldman, D. A., De Luque, M. S., \& Wang, D. (2012). What can we really learn about management practices across firms and countries? Academy of Management Perspectives, 26(1), 34-40. doi:10.5465/amp.2011.0093

Wright, A. L., \& Gilmore, A. (2012). Threshold concepts and conceptions: Student learning in introductory management courses. Journal of Management Education, 36, 614-635. doi:10.1177/1052562911429446 